\title{
THE DIFFERENCES IN COMPARISON OF REAL BODY MASS INDEX AND PERCEIVED BODY-SIZE AMONG ADOLESCENT GIRLS FROM SELECTED SECONDARY SCHOOL
}

\author{
Alžbeta Chovancová, Janka Peráčková \\ Department of Sport Educology and Sport Humanities, Faculty of Physical Education and \\ Sport, Comenius University in Bratislava, Slovakia
}

\begin{abstract}
Summary: The aim of the research was to determine the differences between real body mass index and perceived body-size among adolescent girls from selected secondary schools. We chose the classes from the 4-year secondary school in Bratislava. Girls involved in research were aged between 15 and 18 years. They have been measured in height and weight during the physical education lessons. We calculated the body mass index (BMI). While having them measured, they subsequently received a questionnaire with silhouettes of female figures. They identified one of the body-size about which they felt that most resembling their own body. We found the differences between real BMI and perceived body-size. From the results of our research, we can say that from all of girls (92) only 22 were seen the illustrated female body approximately at the same range as their real BMI. Test of good match - chi square not confirmed $1 \%$ neither $5 \%$ level of statistics significance.
\end{abstract}

Keywords: real BMI, perceived body-size, adolescent girls, secondary school

DOI 10.1515/afepuc-2016-0006

(C) Acta Facultatis Educationis Physicae Universitatis Comenianae 


\section{Introduction}

The human body is the most basic physical instrument by which one may interface with his/her environment, whether it should be internal or external. The body is recognized as an essential channel through which one establishes a sense of self relative to others (e.g., my body versus another's body). Furthermore, the body may be used to communicate basic information about the gender, identity, actions, emotions and even intentions of others

Yet, it is the communication between the human body and brain that allows for the recognition, and interpretation of sensory signals to formulate a consistent understanding of the body, whether it is of one's self or that of another. Body Image is an important element of one's own identity, it is not just how one looks, but how one feels and acts. Body Image is not static concept and can be changed over the lifespan. Merriam-Webster medical dictionary (www.merriam-webster.com) presents medical definition of Body Image: "a subjective picture of one's own physical appearance establishing both by self-observation and by noting the reactions of others."

Western societies generally emphasize thinness, and obese persons tend to have poorer body image and self-esteem (Kindes 2006). There are some evidence in the articles of Hesketh, Wake \& Waters (2004); Swallen, Reither, Haas \& Meier (2005) that Body Mass Index (BMI) is inversely associated with self-esteem for adolescent populations, and age may be a moderator with BMI in predicting self-esteem and psychosocial functioning. Adolescents who were overweight had significantly worse selfreported health as did obese adolescent (Swallen, Reither, Haas \& Meier 2005). Wang, Monteiro and Popkin (2002) examined the trends of overweight and underweight in young persons aged $6-18$ years from 4 countries in selected period of years. They found that the prevalence of overweight increased during the study periods in Brazil, United States and China. The trends of increasing the weight are noticed in big amount of, so called "rich", countries in the world. There is not exception in European countries.

On the other hand, several studies that compared adolescents' perceived weight and height to their actual measures, reported that adolescents were likely to underestimate their weight (Brener, Eaton, Lowry \& McManus 2004). Elgar, Roberts, Tudor-Smith, and 
Moore (2005) leaded research on 418 pupils aged $11-21$ years with this results - based on self-reported data, $13.9 \%$ of the sample was identified as overweight and $2.8 \%$ was identified as obese, but measured data showed rates of $18.7 \%$ and $4.4 \%$ respectively. Underreporting of body weight was found to be more common among female overweight adolescents (Larsen et al. 2008) as well as adolescents with type 2 diabetes (Skinner, Weinberger, Mulvaney, Schlundt \& Rothman 2008). Addressing misperception of weight by adolescents may be the first step to improving weight (ibid). Although underestimating weight may serve as a protective factor for self-esteem, inappropriate weight perception may increase the risk of obesity and obesity-related chronic diseases in adolescents. Underestimation of weight has serious implications that can affect health care behaviours of adolescents, many of whom are at risk for other developing. Underestimation of weight by girls is common across cultures. Adolescents are aware about their physical appearance because of peer slander, peer jealousy, and also dating begins at this age and they want to be liked for the potential partner.

Essentially, people tend to compare themselves with others in society (Festinger 1954), and, people who compare upwards (in this case, comparisons with thinner people and the ideal standard of thinness) on aspects of weight may discover a stigma against obesity and, thus, may tend to have lower self-esteem and body image as a result. They may conclude that they are not as desirable as their thinner counterparts and may, therefore, tend toward lower self-esteem and body image on that basis (Berry, Sheehan, Heschel, Knafl, Melkus \& Grey 2004; Elgar, Roberts, Tudor-Smith \& Moore 2005; Brener, Eaton, Lowry \& McManus 2004; Larsen et al. 2008). If they also have been teased about being obese or overweight, this may tend to result in even lower self-esteem and body image than that experienced by the stigma of obesity alone. Further, if people are prone to having their feelings hurt easily (hypersensitive and emotionally unbalanced), this, too, may relate to lower self-esteem and underestimation of own body image.

The way in which children and adolescents develop a perception of their body and its context within a culture (e.g., acceptable body size and shape, or weight) may have bearing on their relative body satisfaction and self-esteem (Breseman 2004).

Other authors present research on childhood or adolescence and entry into puberty 
as an important developmental step in determining one's body image (Croll 2005; Choudhury, Blakemore \& Charman 2006). According to Heinberg (1996) the numerous changes to the psychological and physical aspects of girls and boys when reaching puberty include how they begin to see their body. Not only do they become more aware of the changes taking place, but they may also begin to perceive their body in terms of cultural standards for ideal fitness and beauty. Heinberg (1996) ventured that girls who matured later (reaching menarche after age 14) tended toward a more positive body image compared to other girls who reached puberty sooner. It appeared that a delay in puberty coincided with a delay in the physical and emotional turmoil associated with maturation.

Obesity research in the United States has consistently shown black girls to be heavier than their white counterparts when matched by age and height (Berry, Sheehan, Heschel, Knafl, Melkus \& Grey 2004), but white girls were more tended to lose weight. It is likely that Jamaican adolescents (most of whom are Black) might be overweight and also might not perceive themselves as overweight. In the research of Paeratakul, White, Williamson, Ryan \& Bray (2002) authors claim that self-perception of overweight was more common in women compared with men and in whites compared with black or Hispanic. Both the correct and incorrect perception of overweight was more common in normal weight and overweight white women. Very similar results were found also in the research of Kakeshita \& de Souza Almeida (2006), where results show that most normal weight or overweight women $(87 \%)$ overestimate their body size while obese women and all men (73\%), regardless of their BMI, underestimated their body-size. Women with the normal weight and overweight were more concerned and uncomfortable with their own body-size. Subjects from the research of Fagaras, Radu \& Rus (2015) reported some dissatisfaction about body shape even they have normal BMI. Body dissatisfactions involved multiple psychological processes and can lead to underestimation, eating disorder and depression. Low self-esteem was perceived by the adolescent participants who were overweight and they expressed mixed feelings and frustration in the research of Bodiba, Madu, Ezeokana \& Nnedum (2008).

\section{Aim}

The purpose of this research was to identify the differences in evaluation between 
real and illustrated Body Mass Index of adolescent girls from selected secondary school.

\section{Methods}

The entire dataset was collected in one day in October 2015. We chose the classes from the 4-year secondary school in Bratislava. Specifically we chose the gymnasium of Jan Papanek on Vazovova street in Bratislava. Girls involved in research were aged between 15 and 18 years. 39 girls from 1. C and 2. C class (younger group) and 53 girls from 3. C and 4. C (older group) were given a questionnaire with a socio-demographic questions and the Rating Scale - Visual Body Composition Analysis Chart (www.chicanol.com) in which were cartoon drawing of seven female silhouettes with the whole body. We chose the seven figures scale, because of Ambrosi-Randić, PokrajacBulian \& Takišić (2005) recommendation that the optimal number of figures on the scale is seven plus (or minus) two. The drawings increase in size from extremely thin 15 to very obese 45 of BMI. Girls were asked with the question: "Which figure looks most like you?" They circled one of the silhouettes on the rating scale of which they considered that most characterize their body in current size (perceived body-size). Respondents selected the figure most closely resembling their body image (Figure 1). Assessment Scale was divided in 7 units of BMI (from 15 to 45 ). The perceptual distortion is defined when an observer is unable to gauge her body size accurately.

Questionnaires with silhouettes were filled on the same day, when adolescent girls were direct measure their height and weight. Each participant's weight was measured using the personal weighting scale, specific Sanitas SBF 48. This scale has a weight capacity of $220 \mathrm{~kg}$. Subjects were weighed in their clothes, but were asked to put off their shoes. Weight was recorded accurate to $0.1 \mathrm{~kg}$. The scale was disinfected after each use. Height was taken in centimetres using a stadiometer. Having measured the height and weight of girls, we calculated from these values the body mass index.

After calculating the actual BMI values we were compared these values with the perception of body size of female characters illustrated in figure 1 . We put these differences into two groups.

1. To a group of girls who have overestimated / have underestimated their bodysize compared to their real BMI (their real BMI was higher or smaller than perceived 
body-size).

2. To a group of girls to be seen as approximately the same as the real (true) value of their BMI was.

We divided girls into two groups of younger adolescent girls (YAG) and older adolescent girls (OAG). In evaluating the results, we used mathematics and statistics methods, specifically test of good match - chi square.

Body Mass Index (BMI) is among the most widely used methods of measuring obesity. It calculated as weight in kilograms divided by the height in meters. In general, it can be considered only as a statistical tool for comparing the population. In a particular individual ignores a number of important factors (e.g. body composition, the amount of muscle, etc.). For European population, the following criteria: to 18,5: malnutrition, 18,5 - 25: ideal and healthy weight, 25 - 30: modestly overweight, $30-40$ : obesity, 40 and over: severe obesity. Boundary values of BMI are different for different ages and races.

Table 1

BMI values for category

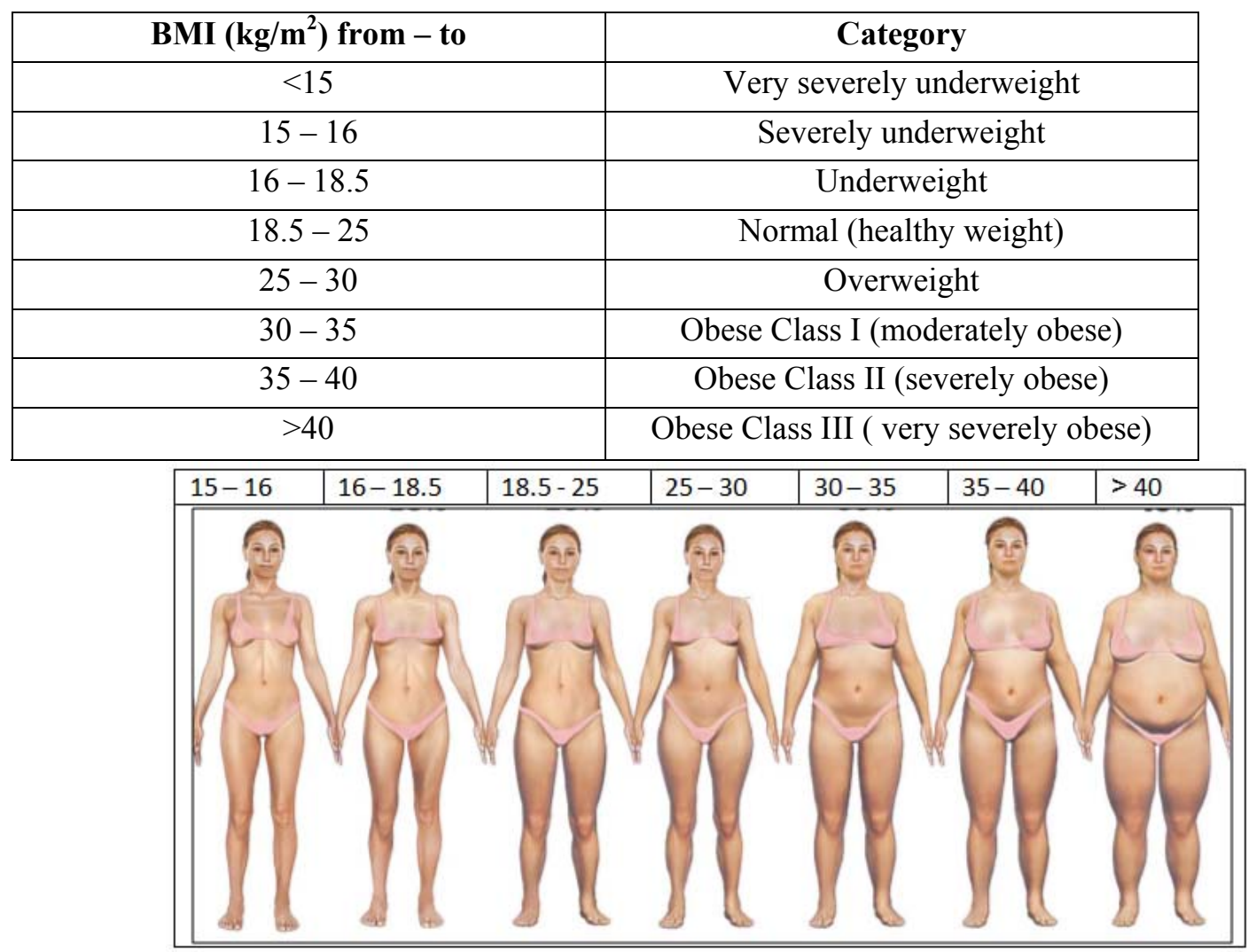

Figure 1 
Silhouettes of woman body for signing the perceived body-size (figure used from: http://www.chicanol.com/wp-content/uploads/2010/03/cartoon-women-and-men-visual-body-

$$
\text { fat.jpg/) }
$$

\section{Results}

From the results of our research, we can say that from all of girls (92) only 22 were seen the illustrated female body approximately at the same range as their real BMI. The differences between younger and older girls' groups were noticed (Table 2).

Table 2

Number of girls of discrepancy in perceived body-size and real measured BMI

\begin{tabular}{|l|c|c|c|}
\hline & $\begin{array}{c}\text { Overestimated/ } \\
\text { underestimated }\end{array}$ & Equality & Sum \\
\hline YAG & 29 & 10 & 39 \\
\hline OAG & 41 & 12 & 53 \\
\hline sum & 70 & 22 & 92 \\
\hline
\end{tabular}

10 girls from YAG rank approximately the same as the fair value of their BMI, compared with 12 girls from the group OAG. The difference between a group of girls who seen themselves as same as their fair value of BMI is not very big. But on the other side in the second group, where the girls underestimate or overestimate compared to the fair value of BMI is greater difference. We see that up to 12 more girls in the group OAG compared to the group of younger adolescent girls.

Test of good match - chi square not confirmed $1 \%$ neither $5 \%$ level of statistics significance. The value we have achieved statistical method was 0.12 . This value was very low. The frequency of $\mathrm{v}=1$, the $5 \%$ level of significance table shows the value of 3.84. Based on this we can say, that the OAG has not evaluated statistically significantly worse compared with their actual BMI values as YAG.

\section{Discussion}

Body Mass Index is considered a crude estimate of body fat since weight includes body fat and muscle tissue. However, BMI as an assessment of obesity in adults has been 
internationally accepted because it correlates well with body fat. In comparing real BMI with perceived BMI from the silhouettes, the findings showed differences among real and perceived BMI more in direction of underestimation of perceived body-size. Very similar results were obtained also in researches of Berry, Sheehan, Heschel, Knafl, Melkus \& Grey (2004), Elgar, Roberts, Tudor-Smith \& Moore (2005), Brener, Eaton, Lowry and McManus (2004), Larsen et al. (2008), Paeratakul, White, Williamson, Ryan \& Bray (2002), Kakeshita \& de Souza Almeida (2006), Fagaras, Radu \& Rus (2015), Bodiba, Madu, Ezeokana \& Nnedum (2008) which we present above in introduction.

The study of Pritchard, King \& Czajka-Narins (1997) examined the relationship between body mass index (BMI) of adolescents and their perceived-weight status and self-concept. From the sample of 17,818 females and 15,878 males they found that the odds of perception of overweight status were higher for females than males. We found the same results in research Muth \& Cash (1997) where relative to men, women had more negative body-image evaluations and body weight and body-image evaluation/affect were linearly related for women, but curvilinearly related for men. Smith \& Cogswell (1994) indicated in their study that Jamaican adolescents are constantly bombarded with pictures of "curvy and plump" Jamaican dancers and performers and the lyrics of the local popular music suggest the attractiveness and desirability of heavier females. In Jamaica it is culturally acceptable to have a large body frame; therefore subjects might not have associated the large body frames of some of the silhouettes as being overweight or obese.

Western European cultures influences the view of adolescent girls on their body. They are exposed to ambient pressure where the presents "ideal beauty" as very slim. Pictures on social networks, the internet and media come into contact every day and provide people with slim and muscular body who want them to resemble. The monitored adolescent big body does not perceive as an attractive compared with Jamaican adolescents and which greater body like and do not perceive it as being overweight or obese.

In U. S. A. survey (Cash \& Henry 1995) nearly one-half of the women reported globally negative evaluation of their appearance and a preoccuparation with being or becoming overweight. But they found that age effects were minimal. Significant effects 
were found in race/ethnicity.

\section{Conclusion}

Our study compared adolescents' perceptions of their body-size to their real BMI. Selected adolescent girl did not right evaluate their weights for perceived body-size in all measured BMI categories: underweight, normal weight, overweight and obese. The inability of adolescent girls to see themselves real but see themselves as overweight or obese may be a major obstacle to promoting healthy lifestyle changes in this age group.

The problem of body image dissatisfaction among adolescent girls is vivid and visible in our research. We compared adolescent girls' perceptions of their body-size with their real BMI. The girls were from selected secondary school from Bratislava. We found the same trend as in other above mentioned researches that more adolescent girls underestimated their weights in comparison to real estimation and overestimation of their real body weight.

In our study to detect a difference between the real BMI and perceived body-size values, we used the appropriate methodology and concluded that we did not confirm the $1 \%$ neither $5 \%$ level of statistical significance that the group of older adolescent girls is not assessed worse than YAG. But we found the perceptual distortion in adolescent girls. Adolescent girls were unable to gauge her body size accurately.

The results from this study may suggest that interventions are needed to achieve the following: improve knowledge of a healthy perceiving of body-size, real weight estimation, encourage the female adolescents to accept their body-size. Recognition of actual body weight status is important for designing and implementing lifestyle changes in acceptance of own body because if somebody dislike own body then he/she dislike $\mathrm{him} /$ herself. We can find the way how to do this in Cash (2008) workbook, where an eight step program for learning to like your looks is presented.

We are aware of the limitations of BMI measurement in relation to body fat percentage, so we also measured the girls' skin folds. The results will be presented in our next article.

\section{References}


1. AMBROSI-RANDIĆ, N., A. POKRAJAC-BULIAN \& V. TAKIŠIĆ, 2005. Nine, seven, five, or three: How many figures do we need for assessing body image? In: Perceptual and Motor Skills. Vol. 100, Issue 2, pp. 488-492.

2. BERRY, D., R. SHEEHAN, R. HESCHEL, K. KNAFL, G. MELKUS \& M. GREY, 2004. Family based interventions for childhood obesity: a review. In: J Fam Nurs, Vol. 10, Issue 4, pp. 429-449.

3. BODIBA, P., S.N. MADU, J.O. EZEOKANA \& O.A. NNEDUM, 2008. The relationsih between body mass index and self-concept among adolescent black female university students. In: Curationis. Vol 31, Issue 1, pp. 77-84.

4. BRENER, N.D., D.K. EATON, R. LOWRY \& T. McMANUS, 2004. The association between weight perception and BMI among high school students. In: Obesity. Vol 12, Issue 11, pp. 1866-1874.

5. BRESEMAN, B.C., 2004. Weight-related teasing: Relationship to body image, selfesteem, and relative body size of adult females: dissertation. Ohio: The Ohio State University.

6. CASH, T.F., 2008. The body Image Workbook: An Eight-Step Program for Learning to Like your Looks. Second edition. Oakland, CA: New Harbinger Publications. ISBN 978-1572245464.

7. CASH, T.F. \& P.E. HENRY, 1995. Women's body images: The results of a national survey in the U.S.A. In: Sex Roles. Vol. 33, Issue 1, pp. 19-28.

8. CHOUDHURY, S., S.J. BLAKEMORE \& T. CHARMAN, 2006. Social cognitive development during adolescence. In: Soc Cogn Affect Neurosci. Vol. 1, Issue 3, pp. $165-174$.

9. CROLL, J., 2005. Body Image and Adolescents. In: STANG, J. \& M. STORY (eds.). Guidelines for Adolescent Nutrition Services. Pp. 155-166. [online], [cited 2015-1201], available on - http://www.epi.umn.edu/let/pubs/adol_ch13.pdf

10. ELGAR, F.J., C. ROBERTS, C. TUDOR-SMITH \& L. MOORE, 2005. Validity of self-reported height and weight and predictors of bias in adolescents. In: J Adoles Health, Vol. 37, Issue 5, pp. 371-375.

11. FAGARAS, P.S., L.E. RADU \& M.C. RUS, 2015. Relation between Body Shape and Body Mass Index. In: $7^{\text {th }}$ World Conference on Education Sciences. Vol 197, pp. 
1458-1463.

12. FESTINGER, L.J., 1954. A theory of social comparison processes. In: Human Relations. Vol. 7, Issue 2, pp. 117-140.

13. HEINBERG, L.J. 1996. Theories of body image disturbance: Perceptual, developmental, and sociocultural factors. In: Body image, eating disorders, and obesity: An integrative guide for assessment and treatment. Washington D.C.: American Psychological Association, 1996.

14. HESKETH, K., M. WAKE \& E. WATERS, 2004. Body mass index and parentreported self-esteem in elementary school children: evidence for a causal relationship. In: Int J Obes Relat Metab Disord. Vol. 28, Issue 10, pp. 1233-1237.

15. KAKESHITA, I.Sh. \& S. de SOUZA ALMEIDA, 2006. Relationship between body mass index and self-perception among university students. In: Rev Saùde Pùblica. Vol. 40, Issue 3, pp. 497-504.

16. KINDES, M., 2006. Body image: new research. New York: Nova Science Publishers Inc.

17. LARSEN, J.K. et al., 2008. Validity of self-reported weight and height and predictor of weight bias in female college students. In: Appetite. Vol. 50, Issue 2-3, pp. 386389.

18. MUTH, J.L. and T.F. CASH, 1997. Body-Image Attitudes: What Difference does gender make? In: Journal of Applied Social Psychology. Vol. 27, Issue 16, pp. 14381452.

19. PAERATAKUL, S., M.A. WHITE, D.A. WILLIAMSON, D.H. RYAN \& G.A. BRAY, 2002. Sex, race/ethnicity, socioeconomic status, and BMI in relation to selfperception of overweight. In: Obes Res. Vol 10.Issue 5, pp. 345-350.

20.PRITCHARD, M.E., S.L. KING \& D.M. CZAJKA-NARINS, 1997. Adolescent body mass indices and self-perception. In: Adolescence. Vol. 32, issue 128, pp. 863-880.

21. SKINNER, A.C., M. WEINBERGER, S. MULVANEY, D. SCHLUNDT \& R.L. ROTHMAN, 2008. Accuracy of perceptions of overweight and relation to self-care behaviors among adolescents with type 2 diabetes and their parents. In: Diabetes Care. Vol. 31, Issue 2. Pp. 227-229.

22. SMITH, D. E. \& C. COGSWELL, 1994. A cross-cultural perspective on adolescent 
girls' body perception. In: Perceptual Motor Skills. Vol. 78, Issue 3, pp. 744-746.

23. SWALLEN, K.C., E.N. REITHER, S.A. HAAS \& A.M. MEIER, 2005. Over-weight, obesity and health related quality of life among adolescents. The National Longitudinal Study of Adolescent Health. In: Pediatrics. Vol. 115, Issue 2, pp. 340347.

24. WANG, Y., C. MONTEIRO \& B.M. POPKIN, 2002. Trends of obesity an underweight in older children and adolescents in the United States, Brazil, China and Russia. In: Am J Clin Nutr. Vol. 75, Issue 6, pp. 971-977.

25. www.chicanol.com. Figure. [online], [cited 2015-12-04], available on http://www.chicanol.com/wp-content/uploads/2010/03/cartoon-women-and-menvisual-body-fat.jpg

26. www.merriam-webster.com. Medical Definition of Body Image. [online], [cited 2015-11-24], available on - http://www.merriamwebster.com/medical/body\%20image 